\title{
Strength of High Volume Matrix using By-Product and Alkaline Aqueous by Electrolysis
}

\author{
Sun-Gyu Park, Sun-A Kim \\ Department of Architectural Engineering, Monwon University \\ 88, Doanbuk-ro, Seo-gu, Daejeon, Korea \\ psg@mokwon.ac.kr; ksa8543@ @aver.com
}

\section{Extended Abstract}

Recently, many studies are actively conducted on high volume cementitious matrix where a large portion of industrial by-products such as blast furnace slag and fly ash are replaced with admixtures to reduce the use of cement [1][2]. Because high volume cementitious matrix using blast furnace slag and fly ash has low early strength, the high volume blast furnace slag and fly ash is not used for building construction materials. In order to secure the early strength of high volume blast furnace slag and fly ash, alkaline activators may be used. However, alkaline activators are dangerous to handle and highpriced [3]. This experimental study has conducted the fundamental research to secure the early strength of high volume blast furnace slag using alkaline aqueous by electrolysis instead of the strong alkaline activator. We carried out compressive strength test, SEM (scanning electronic microscope) test and $\mathrm{XRD}$ (x-ray diffraction) analysis of high volume blast furnace slag matrix activated by alkaline water by electrolysis.

As a result of testing the strength of high volume cementitious matrix using blast furnace slag and alkaline aqueous by electrolysis, the following conclusions were acquired:

(1) In case of high volume cementitious matrix using blast furnace slag and alkaline aqueous by electrolysis, flexural strength and compressive strength were higher than the high volume cementitious matrix using plain water.

(2) As a result of measuring SEM of high volume cementitious matrix, specimen using alkaline aqueous generated more hydrates than the specimen using plain water.

(3) XRD of high volume cementitious matrix using alkaline aqueous showed higher hydrate peaks than that of specimen using plain water.

It was found that alkaline aqueous by electrolysis helps to strengthen the high volume cementitious matrix with blast furnace slag and additional studies wound be necessary to determine the appropriate amount of use and the hydration mechanism of high volume cementitious matrix using blast furnace slag and alkaline aqueous by electrolysis.

\section{Acknowledgements}

This work was supported by the National Research Foundation (NRF) of Korea Grant funded by the Ministry of Education (NRF-2016R1D1A3B03931339).

\section{References}

[1] K. Mehta. P, "High-performance, High-Volume Fly ash Concrete for Sustainable Development," in Proceedings of the Nelu Spiratos Symposium, Committee for the Organization of CANMET/ACI Conferences, 2004.

[2] C. D. Atis, "Strength Properties of High Volume Fly Ash Roller Compacted And Workable Concrete And Influence of Curing Condition," Cement and Concrete Research, vol. 35, no. 6, 2005.

[3] S. S. Lee, Y. M. Kim and S. G. Park, "Strength Properties of Alkali-Activated Lightweight Composites with Alkali Activators of Different Types and Amounts," Journal of the Korea Institute of Building Construction, vol. 14, no. 4, pp. 301-307, 2014. 